\title{
Porous fluid flow enables oceanic subduction initiation on Earth
}

\author{
D. Dymkova ${ }^{1}$ and T. Gerya ${ }^{1}$ \\ Received 4 September 2013; revised 24 October 2013; accepted 28 October 2013; published 14 November 2013.
}

[1] Although most of the presently active intra-oceanic subduction zones are relatively young and initiated during the Cenozoic, subduction initiation process remains poorly understood. Previous models of subduction initiation assumed excessive weakening of tectonic plate boundaries that does not reconcile with laboratory rock strength measurements. The weakening was assumed to be caused by fluids present along tectonic fractures; however no selfconsistent solid-fluid model of subduction initiation has been developed so far. Here we present new numerical hydrothermo-mechanical model of spontaneous intra-oceanic subduction initiation where solid rock deformation and fluid percolation are fully coupled. Based on 2-D numerical experiments, we demonstrate that although subduction fails to initiate under fluid-absent conditions, it can naturally start when porous fluid is present inside oceanic crust and along the plate boundaries. Fluid percolation is localized along spontaneously forming faults where high fluid pressure compensates lithostatic pressure, thus dramatically decreasing friction along the incipient subduction zone. Through the parametric study, we conclude that the most important parameter for subduction initiation is the solid matrix permeability. Paradoxical at first, lowering the permeability indeed favors subduction initiation by maintaining high fluid pressure and thus decreasing friction along active faults. Citation: Dymkova, D., and T. Gerya (2013), Porous fluid flow enables oceanic subduction initiation on Earth, Geophys. Res. Lett., 40, 5671-5676, doi:10.1002/2013GL057798.

\section{Introduction}

[2] The processes governing subduction initiation, although poorly understood and still open for debate, are integral to the plate tectonic regime on Earth [Bercovici, 2003; Gurnis et al., 2004; Nikolaeva et al., 2008]. Nearly half of all the presently active subduction zones have been activated during the Cenozoic, mainly in intra-oceanic environments, indicating that this is a routine process during normal plate tectonic evolution [Gurnis et al., 2004]. Intra-oceanic subduction initiation occurs in a variety of tectonic settings including old fracture zones, transform faults, extinct spreading centers, and back-arc regions of active subduction zones [Casey and Dewey, 1984; Gurnis et al., 2004; Stern, 2004]. In particular, it has been proposed that changes in plate motions and/or lateral buoyancy

Additional supporting information may be found in the online version of this article.

${ }^{1}$ Department of Earth Sciences, ETH Zurich, Zurich, Switzerland.

Corresponding author: D. Dymkova, Department of Earth Sciences, ETH Zurich, H23 NO, Sonneggstrasse 5, Zurich 8092, Switzerland. (diana.dymkova@gmail.com)

(C)2013. American Geophysical Union. All Rights Reserved. 0094-8276/13/10.1002/2013GL057798 contrasts of contacting lithospheric segments are the driver(s) for conversion of transform faults and old oceanic fracture zones into trenches [Casey and Dewey, 1984; Gurnis et al., 2004; Hall et al., 2003; Stern, 2004]. This process was numerically modeled both under conditions of induced plate convergence [Gurnis et al., 2004; Hall et al., 2003] and as a spontaneous buoyancydriven fracture zone collapse [Gerya et al., 2008; Nikolaeva et al., 2008; Zhu et al., 2009]. However, numerical results demonstrated that fracture zones and incipient subduction zones with a very low coefficient of internal friction (0-0.05) are prerequisites for a stable self-sustaining oceanic subduction initiation [Gerya et al., 2008; Hall et al., 2003]. These extremely low values do not reconcile with laboratory strength measurements, suggesting much higher friction coefficients $(0.2-0.85)$ for fractured crustal and mantle rocks [Brace and Kohlstedt, 1980; Byerlee, 1978; Escartin et al., 2001]. For dry fractured crystalline rocks in particular, the friction coefficients are largely independent of composition and varies from 0.85 at pressures below $200 \mathrm{MPa}$ to 0.60 at higher pressures [Brace and Kohlstedt, 1980; Byerlee, 1978] (Byerlee law). It is notably lower (0.15-0.45) [Escartin et al., 2001; Moore et al., 1996, 1997; Reinen et al., 1994] for serpentinized peridotites present at oceanic transform plate boundaries [Gregg et al., 2007; Planert et al., 2007; Roland et al., 2010] yet not low enough to enable self-sustaining subduction initiation. Previous subduction initiation models assumed extreme weakening attributed to fluids present along tectonic fractures [Gerya et al., 2008; Gurnis et al., 2004]. However, the feasibility of this assumption remains open and has not yet been verified on the basis of the self-consistent models [Katz, 2010; Rozhko et al., 2007] coupling solid deformation and fluid percolation during subduction initiation.

[3] This work documents results from the new highresolution 2-D hydro-thermo-mechanical (HTM) numerical models of spontaneous intra-oceanic subduction initiation where solid rock deformation and fluid percolation are fully coupled. In contrast to the previous numerical studies, our HTM numerical models use high brittle/plastic strength of rocks, which is consistent with the laboratory data and directly accounts for the rheological effects of fluids. Selfsustaining oceanic subduction initiation by gravitational fracture zone collapse [Stern, 2004] is systematically reproduced in our numerical experiments. Critical parameters controlling the subduction initiation, such as water content in the oceanic crust and fracture zone, solid matrix permeability, brittle/plastic strength of rocks, plate ages and fracture zone width, are further investigated.

\section{Method}

[4] The computational domain is $600 \mathrm{~km}$ by $250 \mathrm{~km}$ in length and depth, respectively, and has a regular grid 
a

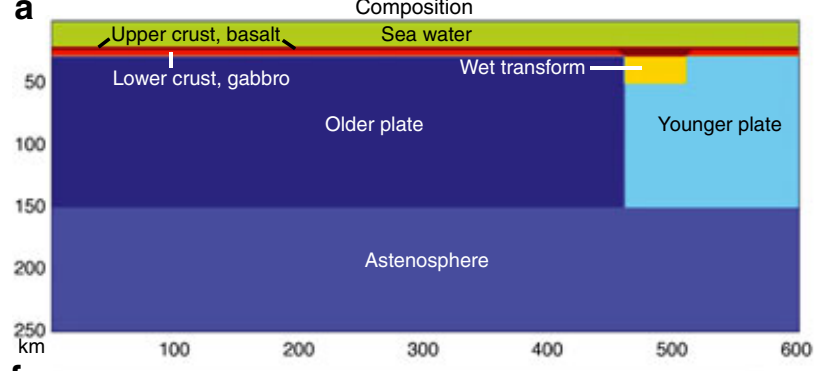

f
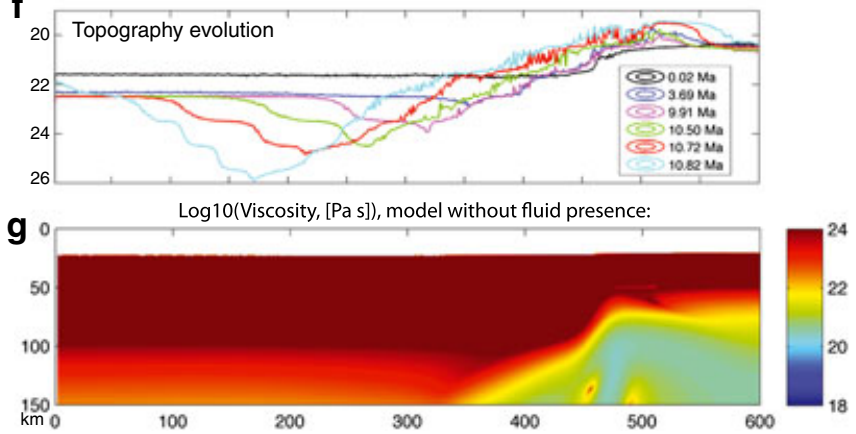

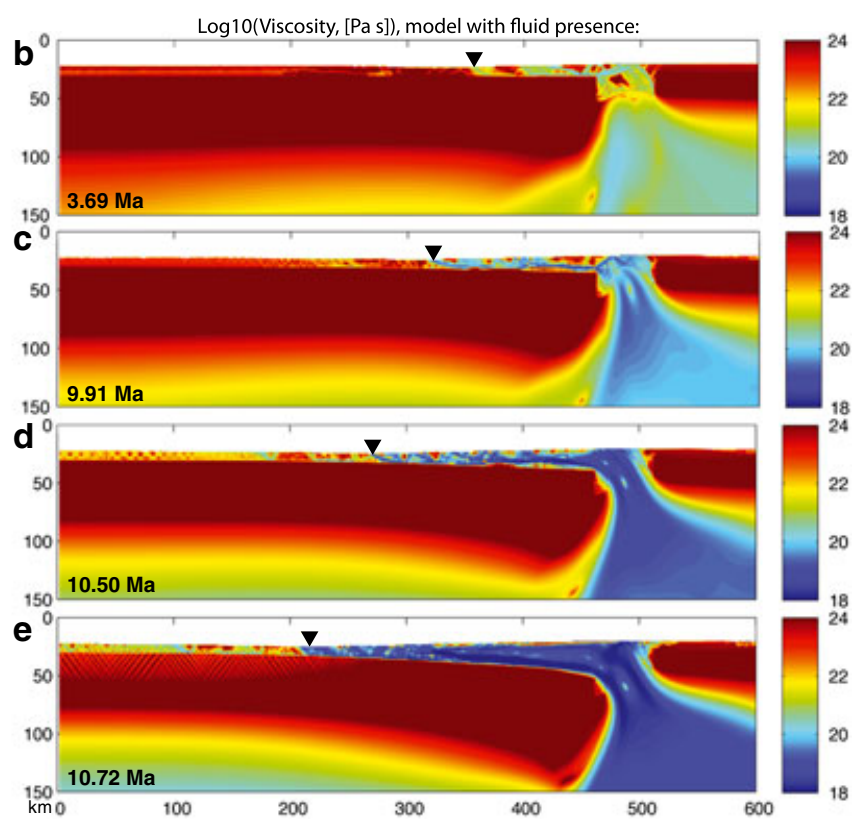

Figure 1. Initial model setup and evolution of subduction initiation for two reference cases: with and without fluid. Black triangle defines the position of trench. Model parameters: porosity of the upper crust and transform fault $1.0 \%$, transform fault width $50 \mathrm{~km}, \gamma=0.4$, ages of the slab and overriding plate 100 and $20 \mathrm{Ma}$, respectively, reference permeability $K_{0}=10^{-21} \mathrm{~m}^{2}$. (a) Initial model setup, lithological map. (b-e) Evolutionary scenario of the model with fluid. (f) Topography development. (g) Evolution of the "dry" model.

resolution of $1 \mathrm{~km} \times 1 \mathrm{~km}$. A tectonic setup representing two oceanic plates of contrasting ages juxtaposed by a transform fault [Hall et al., 2003; Gurnis et al., 2004] (Figure 1a), which has a rectangular shape of 10-50 km width and reaches depths equivalent to the $1300 \mathrm{~K}$ isotherm of the young plate, is used. The fault zone is placed at a distance of 90-130 km (length of the overriding plate) from the right boundary. The initial thermal structure corresponds to cooling ages of the plates [Turcotte and Schubert, 2002]. Upper crust and transform fault materials remain of realistic rheological strength (internal friction coefficient $0.2-0.6)$ and are introduced as porous media filled with fluid at porosity levels of $0.5-3.0 \%$; thus, the fault zone is being considered as deeply hydrated [Korenaga, 2007]. The plate surface is covered with a low-viscosity sea water layer to simulate a free surface [Schmeling et al., 2008; Crameri et al., 2012]. No imposed convergence is applied to the system which is solely driven by the lateral buoyancy contrast of contacting plates with contrasting cooling ages [Stern, 2004].

[5] The system of equations for the coupled solid-fluid flow is based on existing approaches [Bercovici et al., 2001; Domenico and Schwartz, 1990; McKenzie, 1984; Morency et al., 2007; Rozhko et al., 2007; Stevenson and Scott, 1991] (see supporting information) and is reformulated for easier implementation with the finite difference method applied on a fully staggered grid. Fluid filtration through the porous material (Darcy's law) and deformation of the bulk porous fluid-filled matrix are coupled by means of total (bulk) pressure which is defined as [e.g., Morency et al., 2007]

$$
p_{t}=(1-\varphi) p_{s}+\varphi \cdot p_{f},
$$

where $p_{s, f}$ is a solid and fluid pressure respectively and $\varphi$ is matrix porosity. For obtaining the porosity evolution we solve the viscous compaction equation [Bercovici, 2003; Connolly and Podladchikov, 1998]:

$$
\frac{D \ln (1-\varphi)}{D t}=\frac{p_{t}-p_{f}}{\eta_{\text {bulk }}}
$$

where $\eta_{\text {bulk }}=\eta / \varphi$ is bulk viscosity and $\eta$ is shear viscosity of a porous fluid-filled matrix and $D / D t$ is Lagrangian time derivative.

[6] Crustal and mantle rocks have nonlinear viscoplastic rheology (see supporting information), and brittle/plastic deformation is implemented with Drucker-Prager yield criterion where the fluid pressure effect is directly taken into consideration [Ranalli, 1995; Rozhko et al., 2007]:

$$
\sigma_{\text {Yield }}=C+\gamma\left(p_{t}-p_{f}\right)
$$

where $C$ is residual strength at zero pressure, $\gamma$ is internal friction coefficient and $\sigma_{\text {Yield }}$ is a deviatoric stress limit at which brittle/plastic yielding occurs. According to this equation, fluid pressure plays a critical role, significantly reducing brittle/plastic strength of the yielding porous material.

[7] Evolution of flow instabilities during viscous compaction is facilitated by a nonlinear porosity-permeability relationship [Barcilon and Richter, 1986]. Theoretically, functions of permeability depending on porosity can vary from quadratic to cubic [Gueguen and Dienes, 1989], while the value suggested for natural pore distribution is around three [Connolly and Podladchikov, 2000; Morency et al., 2007; Zhu et al., 1995]:

$$
K=K_{0} \cdot\left(\varphi / \varphi_{0}\right)^{3}
$$

where $K_{0}$ is the reference permeability value for $\varphi_{0}=1.0 \%$. 


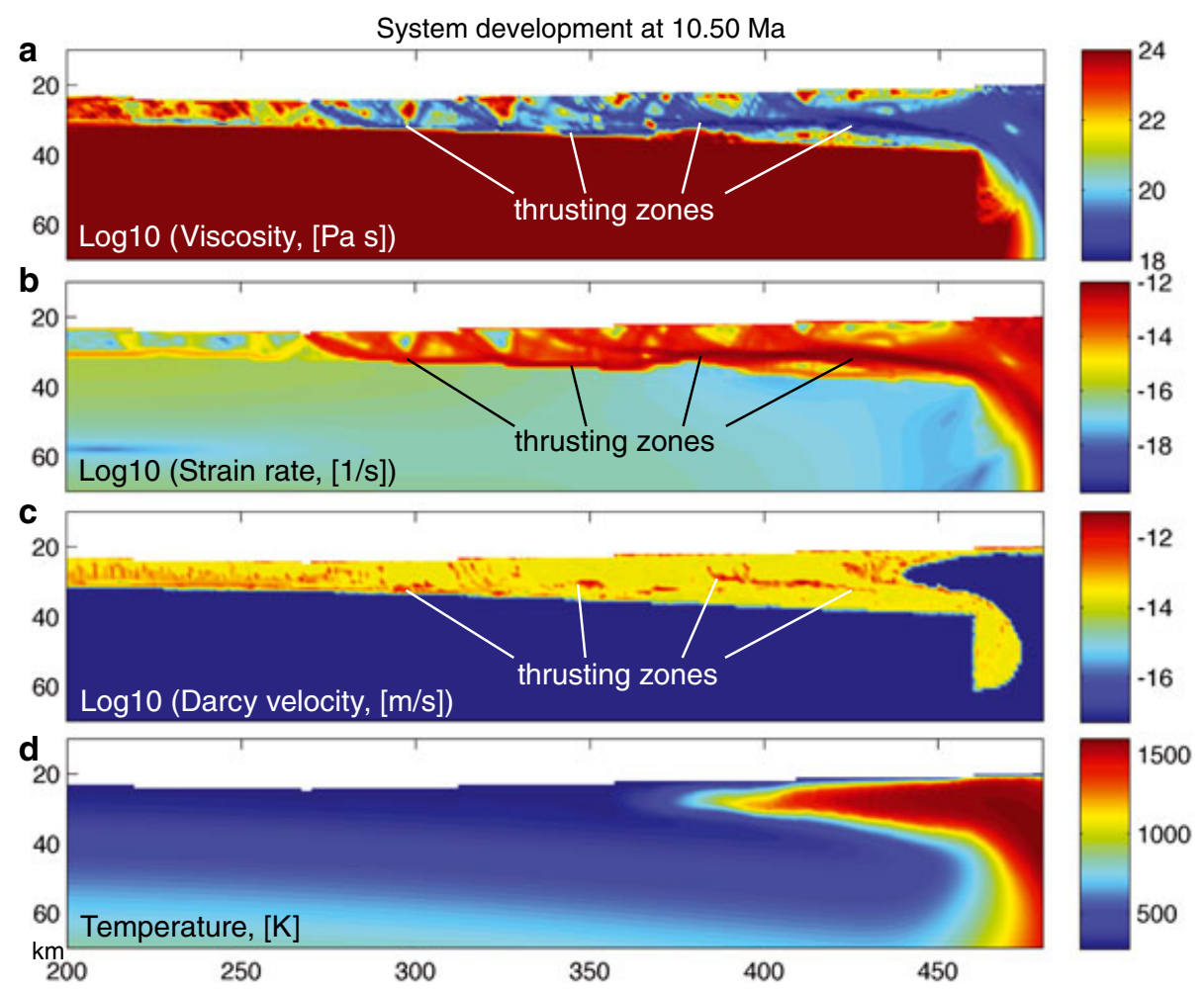

Figure 2. Development of thrusting zones during subduction initiation, detalization of Figure 1d. (a) Viscosity diagram shows that thrusting zones are low-viscosity zones atop the slab. (b) Strain rate diagram shows that the amount of deformation is the highest in the low-viscosity zones. (c) Darcy velocity diagram shows the fluid filtration along the thrusting zones. (d) Temperature diagram shows hot mantle upwelling to the region above the slab.

\section{Results}

[8] In the series of 87 experiments, we have systematically varied width of the transform fault and model parameters such as cooling ages of the plates, porosity, reference permeability, and friction coefficient $(\gamma)$ of hydrated rocks (upper oceanic crust and transform fault). Two reference models, "wet" (Figures 1b-1f) and "dry" (Figure 1g), are compared in Figure 1. In the "wet" model, solid-fluid coupling is taken into account, whereas in the "dry" model, influence of fluid pressure on the brittle/plastic strength of rocks is neglected. All other parameters for these two models are identical. "Wet" model shows spontaneous development of retreating subduction (Figures 1b-1e), whereas a stagnant lid regime develops in the "dry" model (Figure 1g), thus implying critical significance of fluid-induced rheological weakening for oceanic subduction initiation. According to the "wet" model, subduction starts gradually within circa $10 \mathrm{Myr}$ as the negative buoyancy of the downward bending older plate is building up with time [Gurnis et al., 2004] (Figure S1 in the supporting information). During this period, thrusting zones (faults) of low-viscosity, highporosity, and elevated fluid pressure are created atop the older plate (Figure 2), along which deformation (Figure 2b) and fluid flow (Figure 2c) are localized. Once the trench is formed by $3.69 \mathrm{Ma}$, it keeps deepening, but its position is relatively stable till 9.91 Ma, when the older plate starts rapidly sinking (Figure 1c), thus forming a pronounced subducting slab. As hot low-viscosity asthenosphere reaches the region above the slab (Figure 1c and Figure 2d), the downward bending of the slab notably accelerates. The main thrusting zone formed atop of the slab maintains decoupling between the plates and the lubrication of the slab descending. This stage is accompanied by rapid trench rollback continuously accelerating with an average velocity of $16.3 \mathrm{~cm} / \mathrm{yr}$. As a result, the model evolves into a self-sustaining subduction (Figure 1e).

[9] Topography that is being developed (Figure 1f) has realistic trench depths of $\sim 3-4 \mathrm{~km}$, a pronounced forebulge and undergoes through several development stages. Initially, topography is distributed according to the cooling ages prescribed (0.02 Ma curve). During early stage formation of thrust faults, the fore arc region experiences rapid uplift (3.69 Ma curve) followed by a relaxation period after decoupling of plates and beginning of mantle upwelling and overriding plate extension $(9.91 \mathrm{Ma})$. Similar topography evolution was observed in subduction initiation models [Gurnis et al., 2004; Hall et al., 2003] with prescribed plate convergences. At the onset of rapid slab descent, a second stage of uplift associated with overriding plate topography results in further deepening of the trench and roll back of the slab (Figure 1f, curves 10.50, 10.72, and 10.82 Ma) due to the vigorous hot asthenospheric mantle upwelling under the thing overriding the plate (Figure 1d,e).

[10] Our parametric study suggests that reference permeability of hydrated rocks is the main parameter affecting efficiency of solid-fluid rheological coupling and thus oceanic subduction initiation efficiency (Figure 3a). Paradoxical at first, lowering the permeability of rocks indeed favors subduction initiation. Explanation is rather simplehigh permeability of fluid-bearing rocks favors relatively 
a

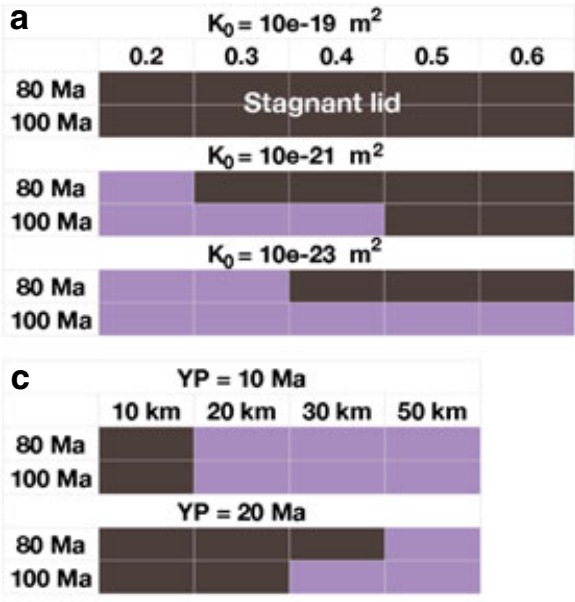

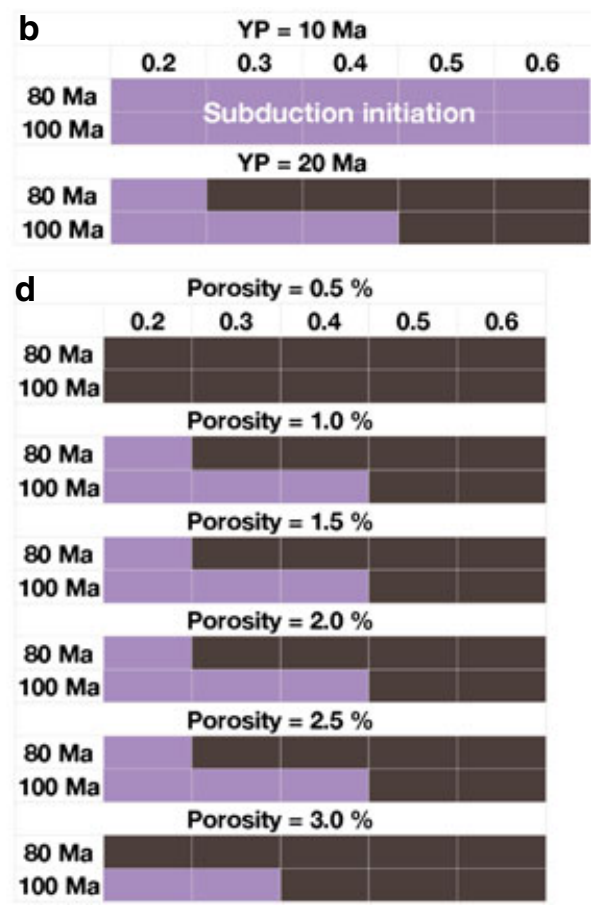

Figure 3. Parametrical study. Vertical scale values signify the age of the subducting slab (Ma); horizontal scale represents either internal friction coefficient $\gamma$ (Figures $3 \mathrm{a}, 3 \mathrm{~b}$, and $3 \mathrm{~d}$ ) or the transform fault width (km; Figure 3c); gray area denotes stagnant lid regime, purple stands for subduction initiation; porosity mentioned is porosity of the upper crust and transform fault. Default model parameters (if not specified on the diagram): porosity of the transform fault and upper crust $1.5 \%$, reference permeability $K_{0}=10^{-21} \mathrm{~m}^{2}, \gamma=0.2$, age of the younger plate $20 \mathrm{Ma}$, and width of the transform fault $50 \mathrm{~km}$. (a) Reference permeability influence. (b) Influence of the younger plate age ("YP," 10 and $20 \mathrm{Ma}$ ). (c) Influence of transform fault width for different younger plate ages (10 and $20 \mathrm{Ma}$ ). (d) Transform fault porosity influence.

low near-hydrostatic fluid pressure, which does not allow for strong lowering of brittle/plastic strength of rocks required for subduction initiation. In contrast, low permeability promotes high (near-lithostatic) fluid pressures, thus providing efficient rheological weakening of coupled solid-fluid system (equation (3)).

[11] Ages of both subducting and overriding plates also have a strong influence on subduction initiation (Figure 3b). Older slabs have greater negative buoyancies and get subducted easier. Likewise, decreasing the age of the overriding plate increases the buoyancy contrast and diminishes the coupling between the plates thus also facilitating subduction initiation. Variance of transform fault width from 10 to $50 \mathrm{~km}$ (and can reach even greater dimensions in case of two closely located serpentinized fracture zones) [Hall et al., 2003] also has a notable influence on the model development: the wider the fault zone, the greater the amount of wet, naturally weakened material between the plates providing intrinsic lubrication, the easier the subduction can be initiated (Figure 3c).

[12] Influence of initial porosity of hydrated rocks on subduction initiation appeared to be more complex (Figures 3c and $3 \mathrm{~d}$ ). On the one hand, initial porosity of the transform should be high enough to provide sufficient amount of water for the formation of the porous thrusting zones along which fluid flow is localized. Porosity, and thus permeability, of fractured rocks should be low enough to maintain high porous fluid pressure which allows for stable slab surface lubrication and decoupling of plates. Since permeability increases with the cube of porosity (equation (4)), steady porosity growth would strongly increase permeability, thus favoring low (near-hydrostatic) rather than high (near-lithostatic) fluid pressure. Results of our experiments suggest (Figure 3c) that for the reference permeability $K_{0}=$ $10^{-21} \mathrm{~m}^{2}$, a porosity range from $1.0 \%$ to $2.5 \%$ is the most propitious for subduction initiation. When porosity goes down to the value of $0.5 \%$, the amount of fluid is not enough to support a mobile lid regime and subduction freezes at initial stage. Likewise, reaching a porosity of $3.0 \%$ rises the magnitude of permeability to a critical limit where fluid pressure does not reach a high enough value to provide rock failure, and henceforth, subduction initiation becomes more difficult.

[13] Our model confirms that deeply hydrated oceanic transforms and fracture zones are favorable settings for subduction initiation [Hall et al., 2003; Gurnis et al., 2004; Stern, 2004; Casey and Dewey, 1984]. According to previous models [Hall et al., 2003; Gurnis et al., 2004], subduction initiation in these settings can be further facilitated by changes in the plate motion providing favorable conditions for activation of initial thrusting and plate lubrication (Figures $1 \mathrm{~b}$ and $1 \mathrm{c}$ ) before turning toward the retreating subduction mode (Figure 1d and 1e). Among a number of recently initiated oceanic subduction zones [Gurnis et al., 2004], the Puysegur-Fiordland subduction zone, southwest of New Zealand, could be considered a good natural example of incipient subduction as it has been initiated in the recent 12-5 Ma [House et al., 2002; Gurnis et al., 2004; Sutherland et al., 2009] at a fracture zone between Australian and Pacific plates. The rapid uplift of 1-2 km 
observed in the Fiordland region is associated with the beginning of the process [House et al., 2002]. Together with the Puysegur trench, reaching depths of approximately 6.5 $\mathrm{km}$ at its deepest point, regional topography forms a similar profile to that we observed in our experiments (Figure 1f). Izu-Bonin-Marianna zone is an example of a more ancient subduction initiation having experienced its infancy period between $\sim 50$ and $35 \mathrm{Ma}$ characterized by remarkably broad initial volcanism of $\sim 200 \mathrm{~km}$ [Hall et al., 2003; Stern and Bloomer, 1992; Gurnis et al., 2004] with high ratios of magma production compared to present-day arcs of $\sim 50 \mathrm{~km}$. The tectonic regime was strongly extensional and is in agreement with our results, similar to Hall et al. [2003], where a broad zone of extension is being formed above the slab subducting at a shallow angle. Hot mantle fills the region above the slab at shallow depth where slab nose dehydration takes place (Figures $2 \mathrm{c}$ and $2 \mathrm{~d}$ ). These conditions are favorable for extended formation of partial melting that could be the plausible explanation for the vast volcanism occurring in the incipient subduction systems. The situation is considerably different from evolved subduction zones, where the subducting plate angle is notably steeper and geotherms above the slab are not as drastic. Our fully coupled HTM solid-fluid subduction initiation model also has some broader implications. In particular, slab bending in our experiments associates with normal faulting and hydration of the slab in the outer rise region (Figures $1 \mathrm{~d}$ and S1). Seismic and heat flow investigations show that there is an active water penetration and deep hydration of the slab in the bending region below the crust-mantle boundary [Grevemeyer et al., 2007; Ranero et al., 2003]. Faccenda et al. [2009] performed numerical modeling of an oceanic subduction using simplified kinematic model of water propagation and showed that bending-related stress changes within the slab produce subhydrostatic pressure gradients along the normal faults, thus providing the downward fluid pumping. In our experiments, this effect is confirmed on the basis of fully coupled solid-fluid model (Figures S2 and S3), in which the excess porous fluid pressure allows for both porous space opening and subsequent downward fluid suction along the bending-related normal faults.

[14] Based on the results achieved, we also expect that implications of the two-phase fluid flow into the highresolution global mantle convection models [Stadler et al., 2010] will allow reproduction of global plate tectonics with single-sided subduction [Crameri et al., 2012] on the basis of laboratory measurements rather than a priori lowered rheological strength of natural rocks.

[15] Acknowledgments. Suggestions of J. Seales and Y. Podladchikov are appreciated. Anonymous reviewers are thanked for their detailed comments on the paper. The research leading to these results has received funding from the EUs FP7 under 287 grant agreement PITN-GA-2008-215353.

[16] The Editor thanks Neil Ribe for his assistance in evaluating this paper.

\section{References}

Barcilon, V., and F. Richter (1986), Non-linear waves in compacting media, J. Fluid Mech., 164, 429-448.

Bercovici, D. (2003), The generation of plate tectonics from mantle convection, Earth Planet. Sci. Lett., 205, 107-121.

Bercovici, D., Y. Ricard, and G. Schubert (2001), A two-phase model for compaction and damage: 1. General theory, J. Geophys. Res., 106, $8887-8906$.
Brace, W., and D. Kohlstedt (1980), Limits on lithospheric stress imposed by laboratory experiments, J. Geophys. Res., 85, 6248-6252.

Byerlee, J. (1978), Friction of rocks, Pure Appl. Geophys., 116, 615-626.

Casey, J., and J. Dewey (1984), Initiation of subduction zones along transform and accreting plate boundaries, triple-junction evolution, and forearc spreading centres-Implications for ophiolitic geology and obduction, Geol. Soc. London Spec. Publ., 13, 269-290.

Connolly, J., and Y. Y. Podladchikov (1998), Compaction-driven fluid flow in viscoelastic rock, Geodinamica Acta, 11(2-3), 55-84.

Connolly, J., and Y. Y. Podladchikov (2000), Temperature-dependent viscoelastic compaction and compartmentalization in sedimentary basins, Tectonophysics, 324, 137-168.

Crameri, F., P. J. Tackley, I. Meilick, T. V. Gerya, and B. J. P. Kaus (2012), A free plate surface and weak oceanic crust produce singlesided subduction on Earth, Geophys. Res. Lett., 39, L03306, doi:10.1029/ 2011 GL050046.

Domenico, P., and F. Schwartz (1990), Physical and Chemical Hydrogeology, John Wiley, New York.

Escartin, J., G. Hirth, and B. Evans (2001), Strength of slightly serpentinized peridotites: Implications for the tectonics of oceanic lithosphere, Geology, 29, 1023-1026.

Faccenda, M., T. Gerya, and L. Burlini (2009), Deep slab hydration induced by bending-related variations in tectonic pressure, Nat. Geosci., 2, 790-793

Gerya, T., J. Connolly, and D. Yuen (2008), Why is terrestrial subduction one-sided?, Geology, 36, 43-46.

Gregg, P., J. Lin, M. Behn, and L. Montési (2007), Spreading rate dependence of gravity anomalies along oceanic transform faults, Nature, 448 , $183-187$

Grevemeyer, I., C. Ranero, E. Flueh, D. Kläschen, and J. Bialas (2007), Passive and active seismological study of bending-related faulting and mantle serpentinization at the Middle America trench, Earth Planet. Sci. Lett., 258, 528-542.

Gueguen, Y., and J. Dienes (1989), Transport properties of rocks from statistics and percolation, Math. Geol., 21, 1-13.

Gurnis, M., C. Hall, and L. Lavier (2004), Evolving force balance during incipient subduction, Geochem. Geophys. Geosyst., 5, Q07001, doi: $10.1029 / 2003 \mathrm{GC} 000681$.

Hall, C., M. Gurnis, M. Sdrolias, L. Lavier, and R. Müller (2003), Catastrophic initiation of subduction following forced convergence across fracture zones, Earth Planet. Sci. Lett., 212, 15-30.

House, M., M. Gurnis, P. Kamp, and R. Sutherland (2002), Uplift in the Fiordland region, New Zealand: Implications for incipient subduction, Science, 297, 2038-2041.

Katz, R. F. (2010), Porosity-driven convection and asymmetry beneath mid-ocean ridges, Geochem. Geophys. Geosyst., 11, Q0AC07, doi:10.1029/2010GC003282.

Korenaga, J. (2007), Thermal cracking and the deep hydration of oceanic lithosphere: A key to the generation of plate tectonics?, J. Geophys. Res. 112, B05408, doi:10.1029/2006JB004502.

McKenzie, D. (1984), The generation and compaction of partially molten rock, J. Petrol., 25, 713-765.

Moore, D. E., D. A. Lockner, R. Summers, S. Ma, and J. D. Byerlee (1996), Strength of chrysotile-serpentinite gouge under hydrothermal conditions: Can it explain a weak San Andreas fault?, Geology, 24, 1041-1044.

Moore, D. E., D. A. Lockner, S. Ma, R. Summers, and J. D. Byerlee (1997), Strengths of serpentinite gouges at elevated temperatures, J. Geophys. Res., 102, 14,787-14,801.

Morency, C., R. S. Huismans, C. Beaumont, and P. Fullsack (2007), A numerical model for coupled fluid flow and matrix deformation with applications to disequilibrium compaction and delta stability, J. Geophys. Res., 112, B10407, doi:10.1029/2006JB004701.

Nikolaeva, K., T. Gerya, and J. Connolly (2008), Numerical modelling of crustal growth in intraoceanic volcanic arcs, Phys. Earth Planet. Inter. $171,336-356$.

Planert, L., E. R. Flueh, and T. J. Reston (2007), Along- and acrossaxis variations in crustal thickness and structure at the Mid-Atlantic Ridge at $5^{\circ} \mathrm{S}$ obtained from wide-angle seismic tomography: Implications for ridge segmentation, J. Geophys. Res., 114, B09102, doi:10.1029/2008JB006103.

Ranalli, G. (1995), Rheology of the Earth, Chapman and Hall, London.

Ranero, J., J. Phipps Morgan, K. McIntosh, and C. Reichert (2003), Bending-related faulting and mantle serpentinization at the Middle America trench, Nature, 425, 367-373.

Reinen, L., J. Weeks, and T. Tullis (1994), The frictional behavior of lizardite and antigorite serpentinites: Experiments, constitutive models, and implications for natural faults, Pure Appl. Geophys., 143, 317-358.

Roland, E., M. D. Behn, and G. Hirth (2010), Thermal-mechanical behavior of oceanic transform faults: Implications for the spatial distribution of seismicity, Geochem. Geophys. Geosyst., 11, Q07001, doi:10.1029/2010GC003034. 


\section{DYMKOVA AND GERYA: POROUS FLUID ENABLES SUBDUCTION}

Rozhko, A. Y., Y. Y. Podladchikov, and F. Renard (2007), Failure patterns caused by localized rise in pore-fluid overpressure and effective strength of rocks, Geophys. Res. Lett., 34, L22304, doi:10.1029/ 2007GL031696.

Schmeling, H., et al. (2008), A benchmark comparison of spontaneous subduction models - Towards a free surface, Phys. Earth Planet. Inter., 171, 198-223.

Stadler, G., M. Gurnis, C. Burstedde, L. Wilcox, L. Alisic, and O. Ghattas (2010), The dynamics of plate tectonics and mantle flow: From local to global scales, Science, 329, 1033-1038.

Stern, R. (2004), Subduction initiation: Spontaneous and induced, Earth Planet. Sci. Lett., 226, 275-292.

Stern, R., and S. Bloomer (1992), Subduction zone infancy: Examples from the Eocene Izu-Bonin-Mariana and Jurassic California arcs, Geol. Soc. Am. Bull., 104, 1621-1636.
Stevenson, D., and D. Scott (1991), Mechanics of fluid-rock systems, Annu. Rev. Fluid Mech., 23, 305-339.

Sutherland, R., M. Gurnis, P. Kamp, and M. House (2009), Regional exhumation history of brittle crust during subduction initiation, Fiordland, southwest New Zealand, and implications for thermochronologic sampling and analysis strategies, Geosphere, 5(5), 409-425.

Turcotte, D., and G. Schubert (2002), Geodynamics, 2nd ed., Cambridge Univ. Press, Cambridge, U. K.

Zhu, G., T. V. Gerya, D. A. Yuen, S. Honda, T. Yoshida, and J. A. D. Connolly (2009), Three-dimensional dynamics of hydrous thermal-chemical plumes in oceanic subduction zones, Geochem. Geophys. Geosyst., 10 Q11006, doi:10.1029/2009GC002625.

Zhu, W., C. David, and T.-F. Wong (1995), Network modelling of permeability evolution during cementation and hot isostatic pressing, $J$. Geophys. Res., 100, 15,451-15,464. 